\author{
Military Technical College \\ Kobry El-Kobbah \\ Cairo, Egypt
}

$10^{\text {th }}$ International Conference

On Aerospace Sciences\&

Aviation Technology

\title{
Theoretical And Expermintal Sensitivity Analysis And Control Of Hydrostatic Transmission System
}

\author{
Saber M.*, El-mashed Y.A.**, Abd Rabbo S.*** and Osman A.M.** \\ * Associate lecture, Mech. Eng. Dept., Shubra Faculty of Eng. Zagazig University \\ ** Associate Professor, Mech. Eng. Dept., Shubra Faculty of Eng. Zagazig University \\ *** Assistant Professor, Mechatronics Eng. Dept., Phildelphia University, Jorden \\ E-mail:Saberabdrabbo1@hotmail.com moh_sokar@hotmail.com
}

\begin{abstract}
Dynamic behaviors of the Hydro-Static Transmission (HST) systems are studied expermintally and theoritically. A linearised mathematical model of HST system is formulated. Parametric sensitivity using state variable analysis has been shown that there are two dominanat poles. The damping ratios associated with these polesare reduced by a noticeable percent when bulks modulus and volumatric displacement of the hydraulic motor are changed by $\pm 20 \%$ of its nominal value, while an increase in leakage can lead to unstable system. A computer controlled test rig is developed and the response of the system states are measured. Experimental response of the system states are compared with the simulated results. The performance is improved after introducing Linear Quadratic Regulator (LQR) controller. The work outlined in this research represents a step in the optimal design process of hydrostatic transmission system.
\end{abstract}

\section{Key Words}

Hydrostatic transmission (HST), Mathematical model, Sensitivity analysis, Linear Quadratic Regulator (LQR), Leakage. 


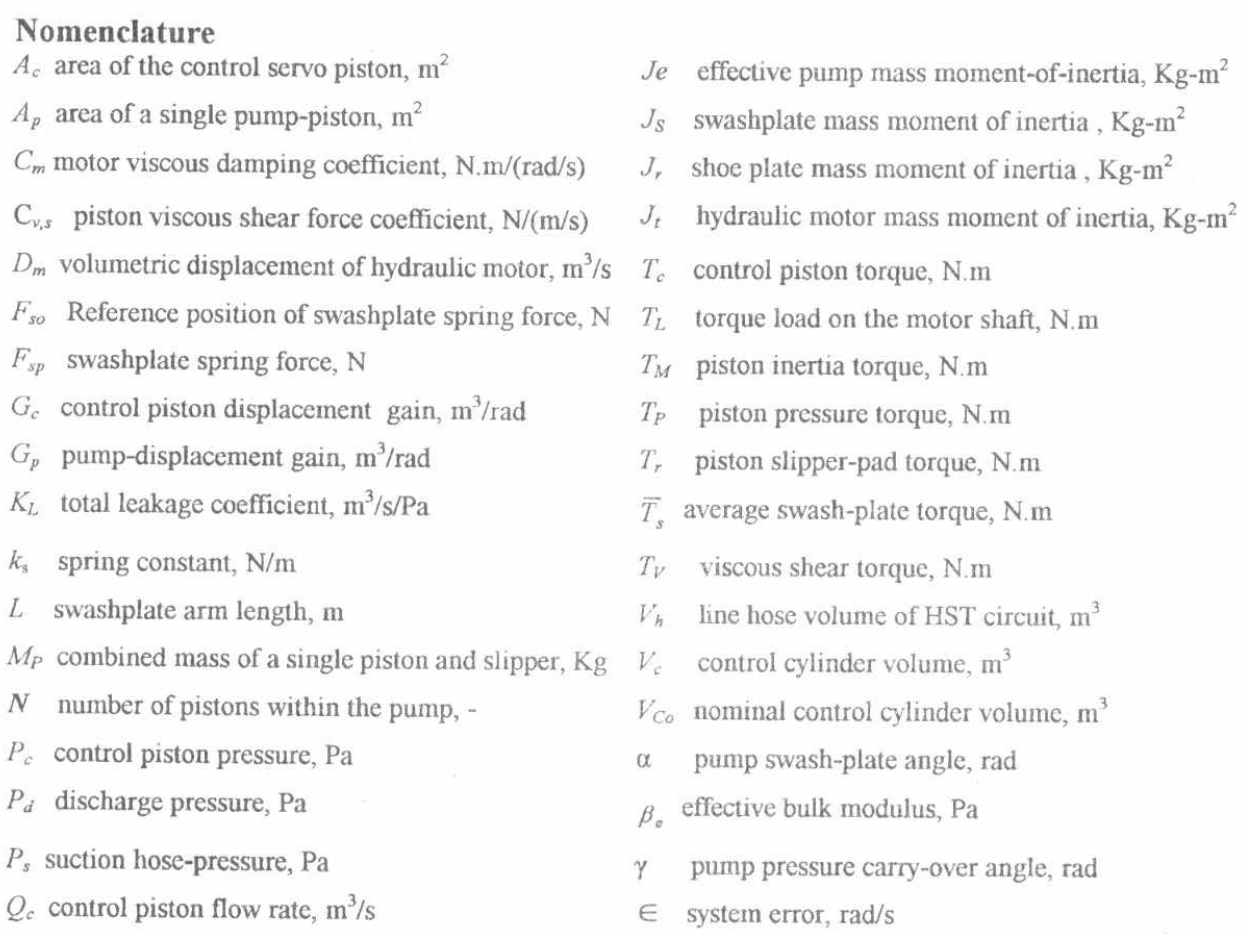

\section{1-Intoduction}

Hydrostatic transmission (HST) is one of the most important application in the filed of fluid power systems. Hydrostatic transmission can give smooth change of output speed, output torque and output power according to the design requirements. Hydrostatic transmission are used to transmit rotating mechanical power from one source to another without use of gears in stepless mannar. Hydrostatic transmissions are often used for speed control where large load-torque fluctuations may cause unacceptable changes in the output speed, also where the design of gears train may be undesirable or impossible. Manring N. D. and Luecke G. R., [1], developed a dynamic model of HST by using a linear model to study the dynamics utilizing a variable-displacement axial-piston pump with a fixed displacement motor. The equations that describe the dynamics of the motor, the hoses, and pump behaved as a third-order linear system. The output speed of the motor were changed by considering a constant low pressure side $P_{s}$, and a variable high pressre side $P_{d}$. The model neglect system leakage and motor viscus coefficients. Huhtala K., [2], developed a steady state, models of different hydraulic components of hydrostatic transmission. Simulation models of different hydraulic componentsand the complete hydrostatic transmission system including diesel engine are verified with measured data. Kim S. D. et al [3] presented parameter sensitivity analysis for the dynamic model of a variable displacement axial piston pump, parameter sensitivity analysis was employed to analyze the nonlinear model of the pump with decoupled manner. Njabeleke I. A. et al., [4, 5], presented application of robust control model to control HST. a multi-mode controller made up of two controllers one for high speeds used to describe valve openings over $20 \%$ and one for low speeds to describe valve 
openings of under $20 \%$. Heinz Mueller, [6], was described control regulating systems of hydrostatic transmissions in closed loop with automatic torque conversion and power limitations.

This study presents sensitivity analysis of HST system starting by developing a linearized mathematical model which describe the dynamics of the system, the effect of the system parameter variation were studied. The study proposed suitable design of robust controller, and an expermintal computer controlled test model was built to validate such work by considering constant pump speed and variable hydraulic motor speed.

\section{2- Governing equations}

The Governing equations describe the studied hydrostatic transmission system shown in figure (1) can be formulated as follows;

2.1 Hydraulic motor equations

The torque balance equation is

$$
\begin{aligned}
& J \ddot{\theta}=\sum T_{\text {external }}=\text { generated torque }- \text { losses torque }- \text { load torque } \\
& J_{t} \frac{d \omega}{d t}=T_{t h}-T_{v}-T_{f}-T_{L} \\
& \dot{\omega}_{m}=-\frac{C_{m}}{J_{t}} \omega_{m}+\frac{D_{m}}{J_{t}} P_{d}-\left(\frac{D_{m} P_{s}+T_{L}}{J_{t}}\right)
\end{aligned}
$$

2.2 Hydraulic lines equations

The flow continuity equation for the hydraulic line is;

$$
Q_{p}-Q_{m}-Q_{L}=\frac{V_{h}}{\beta_{e}} \frac{d P_{d}}{d t}
$$

where $Q_{p}, Q_{m}$ and $Q_{L}$ are pump, motor and leakage flow rates respectively. The final pressure rise equation of the hydraulic pump becomes;

$$
\dot{P}_{d}=\frac{\beta}{V_{h}}\left(G_{p} \alpha-D_{m} \omega_{m}-K_{L} P_{h}\right)
$$

\subsection{Pump equations}

A illustrated in figure (2), the force that act on the swashplate are the inertia of the swashplate, stiffness of the spring and force of servo control pressure, hence the swashplate torque balance equation is

$$
J_{s} \ddot{\alpha}=\sum \text { Texternal }
$$

Where,

$$
T_{\text {external }}=\bar{T}_{s}-T_{s p}+T_{c}
$$

Hence the equation of motion of the swashplate is

$$
J_{s} \ddot{\alpha}=\bar{T}_{s}-T_{s p}+T_{c}
$$

\section{Swashplate torque}

This average swivel torque $\bar{T}_{s}$, consists of four parts, piston inertia effect $T_{M}$, piston viscous shear effect $T_{V}$, piston shoe-plate (Slipper pad) torque $T_{r}[7]$, and pressure force effect $T_{P}$, it may be written as: 


$$
\bar{T}_{s}=T_{M}+T_{V}+T_{r}+T_{P}
$$

The linearized version of induced average swashplate torque can be given as;

$$
\bar{T}_{s}=-J_{e} \ddot{\alpha}-C_{V} \dot{\alpha}+K_{i} \alpha-K_{p}\left(P_{d}-P_{s}\right)
$$

where,

$$
J_{e}=J_{r}+\frac{N \cdot M_{p} \cdot R^{2}}{2}, \quad C_{v}=\frac{N \cdot C_{v s} \cdot R^{2}}{2}, \quad K_{p}=\frac{N \cdot A_{p} \cdot R \cdot \gamma}{2 \pi} \text { and } \quad K_{i}=\frac{N \cdot M_{p}}{2} \omega_{p}{ }^{2} R^{2}
$$

Return spring torque of control actuator

In general the spring force can be expressed as

$$
F_{s p}=F_{s o}-k_{s} L \sin \alpha
$$

Then, the spring torque can be expressed as:

$$
T_{s p}=F_{s o} L-k_{s} L^{2} \sin \alpha
$$

\section{Control piston torque}

The control piston is the actuator that controls pump displacement as shown in figure (2). The flow continuity equation for the control volume of cylinder control pressure can be expressed as;

$$
\text { if } \quad \begin{aligned}
\dot{P}_{c} & =\frac{\beta}{V_{c o}}\left(Q_{c}-\dot{V}_{c}\right) \\
\epsilon & =\omega_{r}-\omega_{m}
\end{aligned}
$$

Where, $\omega_{r}$, Reference motor shaft- desired speed

The net flow into the servo can be expressed as;

$$
Q_{c}=G_{c} \in
$$

$$
P_{c}=\frac{\beta_{e}}{V_{c o}} G_{c} \int \in d t-\frac{\beta_{e}}{V_{c o}} A_{c} L \tan \alpha+P_{c o}
$$

The general control piston torque is:

$$
\begin{aligned}
& T_{c}=F_{c} \cdot L=P_{c} A_{c} \cdot L \quad \text {, for small angle } \tan \alpha=\alpha \\
& T_{c}=\left[\frac{\beta_{e}}{V_{c o}} G_{c} \int \epsilon d t-\frac{\beta_{e}}{V_{c o}} A_{c} L l \alpha+P_{c o}\right] A_{c} \cdot L \\
& J_{s} \ddot{\alpha}=-J_{e} \ddot{\alpha}-C_{V} \dot{\alpha}+K_{i} \alpha-K_{p}\left(P_{d}-P_{s}\right)-\left(F_{s o} L+k_{s} L^{2} \alpha\right) \\
& +\left(\frac{\beta_{e}}{V_{c o}} G_{c} \int \in d t-\frac{\beta_{e}}{V_{c o}} A_{c} L \alpha+P_{c o}\right) A_{c} L
\end{aligned}
$$

Then, the complete equation of the pump is expressed as

$J_{\text {eff }} \ddot{\alpha}+C_{\text {eff }} \dot{\alpha}+K_{\text {eff }} \alpha=K_{1}-K_{p}\left(P_{d}-P_{s}\right)+K_{2} \int \epsilon d t$

Where, $J_{e f f}=J_{s}+J_{e}, \quad C_{e f f}=C_{V}$

$$
K_{1}=\left(P_{c o} A_{c}-F_{s o}\right) L, \quad \text { and } \quad K_{2}=\frac{\beta}{V_{c o}} G_{c} A_{c} L
$$

In practice, the change in speed of swashplate is constant, then by differentiation equation (17) and rearranging, it becomes

$$
\dot{\alpha}=\frac{1}{K_{e f f}}\left[\left(\frac{K_{p} D_{m} \beta_{e}}{V_{h}}-K_{2}\right) \omega_{m}+\frac{K_{p} K_{L} \beta_{e}}{V_{h}} P_{d}-\frac{K_{p} G_{p} \beta_{e}}{V_{h}} \alpha+K_{2} \omega_{r}\right]
$$


To represent the final governing equations (2), (4), and (18) into a state space form, the state variable vector $x$, and input vector $\boldsymbol{u}$ will be defined as;

$\left[\begin{array}{l}x_{1} \\ x_{2} \\ x_{3}\end{array}\right]=\left[\begin{array}{c}\omega_{m} \\ P_{d} \\ \alpha\end{array}\right] \quad$ and, $\quad\left[\begin{array}{l}u_{1} \\ u_{2}\end{array}\right]=\left[\begin{array}{c}\omega_{r} \\ T_{L}\end{array}\right]$

The state space equation takes the form;

$\left[\begin{array}{l}\dot{\omega}_{m} \\ \dot{P}_{d} \\ \dot{\alpha}\end{array}\right]=\left[\begin{array}{lll}a_{11} & a_{12} & a_{13} \\ a_{21} & a_{22} & a_{23} \\ a_{31} & a_{32} & a_{33}\end{array}\right]\left[\begin{array}{l}\omega_{m} \\ P_{d} \\ \alpha\end{array}\right]+\left[\begin{array}{cc}0.0 & -b_{12} \\ 0.0 & 0.0 \\ b_{31} & 0.0\end{array}\right]\left[\begin{array}{l}\omega_{r} \\ T_{L}\end{array}\right]$

where,

$$
\begin{aligned}
& a_{11}=-\frac{C_{m}}{J_{t}}, \quad a_{12}=\frac{D_{m}}{J_{t}}, \quad a_{13}=0, \quad a_{21}=-\frac{\beta_{e}}{V_{h}} D_{m}, \quad a_{22}=-\frac{\beta_{e}}{V_{h}} K_{L}, \quad a_{23}=-\frac{\beta_{e}}{V_{h}} G_{p} \\
& a_{31}=\left(\frac{K_{p} \beta_{e}}{K_{e f f} V_{h}} D_{m}-\frac{K_{2}}{K_{e f f}}\right), \quad a_{32}=\frac{K_{p} K_{L} \beta_{e}}{K_{e f f} V_{h}}, \quad a_{33}=-\frac{K_{p} G_{p} \beta_{e}}{K_{e f f} V_{h}} b_{12}=\frac{1}{J_{t}} \quad b_{31}=-\frac{K_{2}}{K_{e f f}}
\end{aligned}
$$

The terms in the mathematical model, which presented in the previous sections were determined using physical and geometrical data furnished by Mannesmann Rexroth Group on their series hydraulic pump, and hydraulic motor. Some parameters in the equation depend on the geometrical data of the A4VTG hydraulic pump [8] and the A2FM hydraulic motor [9] supplied by the manufacturer as depicted in table (1).

\section{3- Model validation}

The obtained results from the presented model are compared with results of Manring et al [1]. The response curves of motor speed, dlivery pressure, and swashplate angle indicate that, the two models almost have the same settling time while there is a noticeable improvement in maximum overshoot, as shown in figure (3).

\section{4- Experimental test rig and results}

A schematic representation for the experimental test rig of the hydrostatic transmission system that is being considered in this study is illustrated in figure (4) also a photograph of the test rig is shown in figure (5). In this present work the control of the pump speed is passive, i.e., constant pump speed. The test rig has the following components:

- Prime mover is a three-phase induction AC motor $30 \mathrm{hp}, 1450 \mathrm{rpm}$.

- Reversible variable displacement axial piston pump, type A4VTG (MANNESMANN REXROTH Group) with maximum displacement $71 \mathrm{~cm}^{3} / \mathrm{rev}$.

- Proportional electrohydraulic servo position, this is a displacement control installed on pump and it allows the electronic variation of the displacement volume via control the position of the swashplate. The magnitude of the pump displacement is in proportion to the swashplate:

- Fixed displacement axial piston hydraulic motor (bent-axis A2FM type), with a maximum displacement $63 \mathrm{~cm}^{3} / \mathrm{rev}$. The hydraulic motor directly rotates the load.

- Load torque, it consists of iron discs, the inertia of the load can be altered by changing the number of iron discs. In addition, a hysteresis brake is used to exert a 
disturbance torque on the hydraulic motor shaft to test the system's capacity of disturbance rejection.

-A Data Acquisition Card (DAQ), Das-1600/1400 series by KEITHLEY Instruments, Inc. The control signal from the input data are sent to the pump displacement controller via a 12-bit D/A converter. Interfaced with a PC computer, were used to acquire the signals line hose pressure, and motor speed. These two response signals from hydraulic motor speed $\left(y_{1}\right)$, and line hose pressure $\left(y_{2}\right)$, were acquired by two input channels of the KEITHLEY DAQ and recorded in the computer

Test conditions are :

$\square$ Through the simulation and experiments, the command input of the motor speed, $\omega_{r}$ is $150 \mathrm{rad} / \mathrm{s}(1430 \mathrm{rpm})$.

$\checkmark$ During the experiment the temperature of the fluid was obtained at $50 \pm 2^{\circ} \mathrm{C}$ after $1 / 2$ hours.

\section{Measurement apparatus}

Inductive non-touch type sensor, which is mounted at the end of the motor shaft. The speed of the hydraulic motor is sensed by it. The output of the sensor is, meanwhile, fed back, to DAQ and this forms closed loop for speed control. Pressure transducer, connected to the pump outlet to record the pressure signal, its output signals are sent to the DAQ. The outputs of these stated transducers were sent to PC/ATX microcomputer CPU PII-333 Mhz via an 12-bit AVD converter card.

\section{Experimental results}

In order to verify the described results the test rig was set up as described in section (4). This model has been verified by experimental step response tests. The experimental as well as theoretical steady state characteristics are compared in figure (6) which show Close agreements between measured and simulated results.

\section{5- Simulation results and Sensitivity analysis}

This chapter introduces the effect of varying parameter on transient performance and closed loop poles. This is done by a series of simulation studies with small variation of parameters by $\pm 20 \%$ of its nominal value to show that the model is justified with practical range of operating conditions. Changes in system dynamics would hardly influence the response at all. In order to verify this, step responses in a number of varying parameters were studied. A further examination of hydrostatic transmission system by sensitivity analyses, through means of simulation studies to investigate the effect of parameter variation on the steady state performance, is performed and depicted from figure (7) to figure (12).

A graphical method is introduced for plotting the locus of the roots in the s-plane as a system parameter is varied over specified range of values for most effected parameters are shown in figure (13) to figure (18).

Based upon investigation of the system response and eigenvalues. Table (2) illustrates changes in system response characteristics that can be expected when various parameters are increased. For instance, from table (2) it can be seen that by increasing the leakage coefficient, $K_{L}$, the system rise-time is unaffected $(-)$, small change in peak time $(\cong)$, the maximum percent-overshoot is increased $(\Delta)$, and 
the system settling-time is increased $(\Delta)$. Conversely, it should be assumed that by decreasing this same parameter an opposite effect would be exhibited for these specifications.

\section{6- Design of Optimal Linear Quadratic Regulator (LQR) system}

In this approach the quadratic performance index is minimized.

Assume the state feedback control vector or the external force in the form

$$
u(t)=-K \quad x(t)
$$

The quadratic performance index defined as follows;

$$
J=\int_{0}^{\infty}\left(x^{T} Q x+u^{T} R u\right) d t
$$

The first term under the integral is the penalty for $x$ not being zero, the second, the cost of the external force $u$ applied accounts for the expenditure of the control signal energy.

Where, $K$ is an $r \times n$ state feedback matrix, $r$, refers to the number of input

$Q$ is at least positive-semidefinite Hermitian or real symmetric matrix.

$R$ is a positive-definite Hermitian or real symmetric matrix.

From parameter optimization problem, we set

$$
x^{T}\left(Q+K^{T} R K\right) x=-\frac{d}{d t}\left(x^{T} P x\right)
$$

Where, $\mathrm{P}$ is positive-definite Hermitian or real symmetric matrix which must satisfy the following Riccati equation

$$
A^{T} P+P A-P B R^{-1} B^{T} P+Q=0
$$

The design steps are to determine matrix $Q$, it is examined by computer simulation, the response characteristics of the system for several different matrices $Q$, which is not unique for a given system, but depend on $R$. We keep $R$ fixed and study how the response changes when we change the value of $Q$. The criterion for choosing matrix $Q$ is to give the optimum overall system performance, which depends on the particular situation, including economic considerations. We choose the one that gives the best overall system performance based on trail and error method; they are:

$Q=\left[\begin{array}{ccc}10 & 0 & 0 \\ 0 & 1 & 0 \\ 0 & 0 & 100\end{array}\right]$

and,

$R=[1]$

Figures (19) Shows a step response of the three states designed by LQR compared to the nominal steady state one. The results show an improvement in system response. The obtained control low becomes;

$$
\left[\begin{array}{l}
u_{1} \\
u_{2} \\
u_{3}
\end{array}\right]=\left[\begin{array}{llc}
262.755 & 0.000912 & -113.365 \\
-300.71 & 2.54863 & 85.5654
\end{array}\right]\left[\begin{array}{l}
x_{1} \\
x_{2} \\
x_{3}
\end{array}\right]
$$




\section{7- Conclusions}

The work presented in this study represents a step in the microscopic view into the dynamic properties of HST system. The derived mathematical model of the system is composed of a set of differential equations. The feature of the proposed model is that it enables the equations to be written in linearized form, hence a state variable model is then achieved. The response of the system states are measured experimentally and the effect of dynamic parameters variations on the dynamic behaviour are studied extensively. Comparison between the theoretical simulation and the experimental responses of the HST system are seen, to match adequately. The establishment of the simulation analysis and experimental verification reveal that increasing the leakage, leads to unstable systems. On the other hand keeping bulk modules and volumetric displacement of the hydraulic motor as high as possible decrease the fluctuation of working pressure, improve the performance of speed control. Design a LQR with state feedback improve system performance as achieved in simulation. The work outlined here regard as a step in the investigation of design procedure of optimal control for hydrostatic transmission systems.

\section{References}

[1] Manring, N. D., and G. R. Lueke, "Modeling and Designing a Hydrostatic Transmission with a fixed-Displacement Motor, "Journal of Dynamic Systems, Measurement, and Control, Vol. 120, pp. 45-49, March 1998.

[2] Huhtala, K., "Modeling of hydrostatic transmission - steady-state, linear and non-linear models," Doctor thesis, Acta Polytechnica Scandinavica, Mechanical Engineering Series, No. 123, FIN-33101 Tampere University of technolgy, Finland, 1996, $101 \mathrm{pp}$.

[3] Kim, S. D., H. S. Cho, and C. O. Lee, 1987, "A Parameter Sensitivity Analysis for the Dynamic Model of a Variable Displacement Axial Piston Pump," Proceedings of the Institution of Mechanical Engineers, Vol. 201 No. C4: pp. 235-243.

[4] Njabeleke, LA., "Fluid Power Systems-An Integrated Approach: Control System Design-Part I: $H_{\infty}$ Approach", Report No 18/1997, Fluid Power Centre, University of Bath.

[5] Njabeleke, I. A et al, "Modeling and control of a high speed hydrostatic transmission," Proceedings of the 1998 ASME. VOL. 51998 Anaheim, CA, ,USA pp. 1-10.

[6] Heinz Mueller, "Hydrostatic transmission and control for wheeled vehicles, " SAE, 0096-736x, Vol. 4, pp. 1072-1082, 1985

[7] Harris R. M. et al, "Predicting the behaviour of slipper pad in swashplate type axial piston pumps", Journal of Dynamic Systems, Measurement and Control, Vol. 118 pp.1072-1081, 1995.

[8] Product catalouge: Hydraulic pump A4VTG of Mannesmann Rexroth International Ltd., RE 92012/04.00, Technical information Augest 2000

[9] Product catalouge: Hydraulic motor A2FM of Mannesmann Rexroth International Ltd., RE 92012/04.00, Technical information Augest 2000 


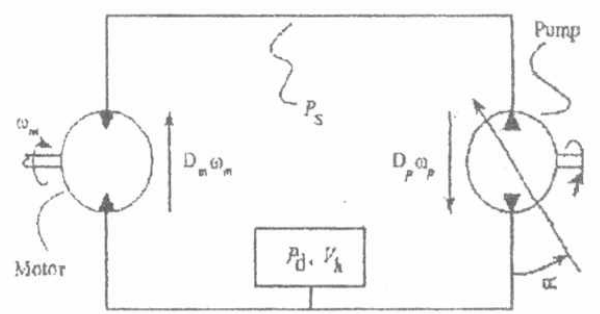

Figure (1) Schematic diagram of Hydrostatictransmission system.
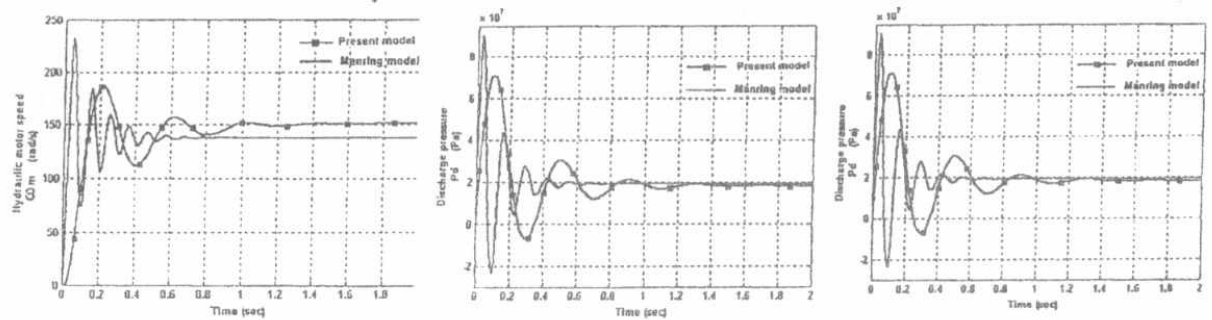

Figure (3) Variation of discharge pressure, swashplate angle, and hydraulic motor speed verses time for the proposed model compared with manring [1] model
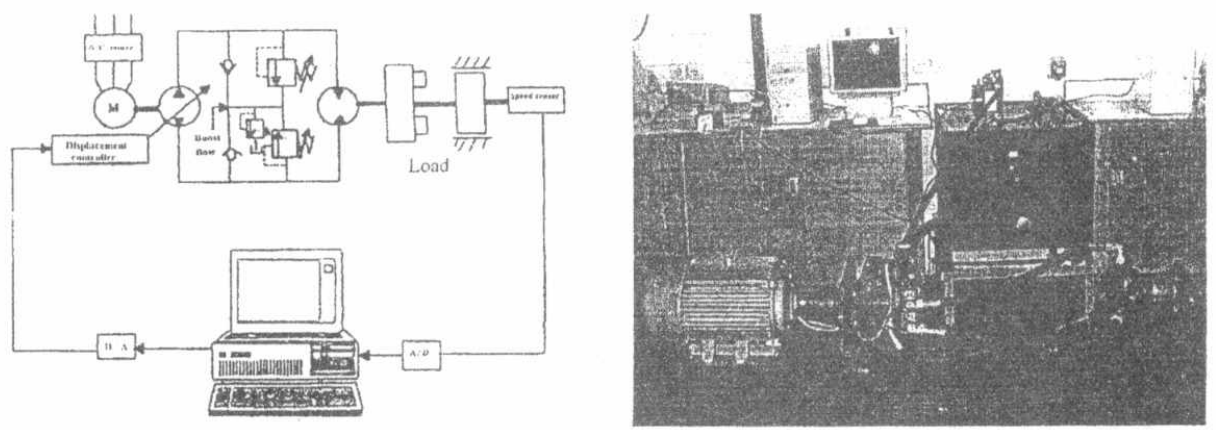

Figure(4) A schematic of the experimental test rig

Figure (5) A photograph for HST system test rig
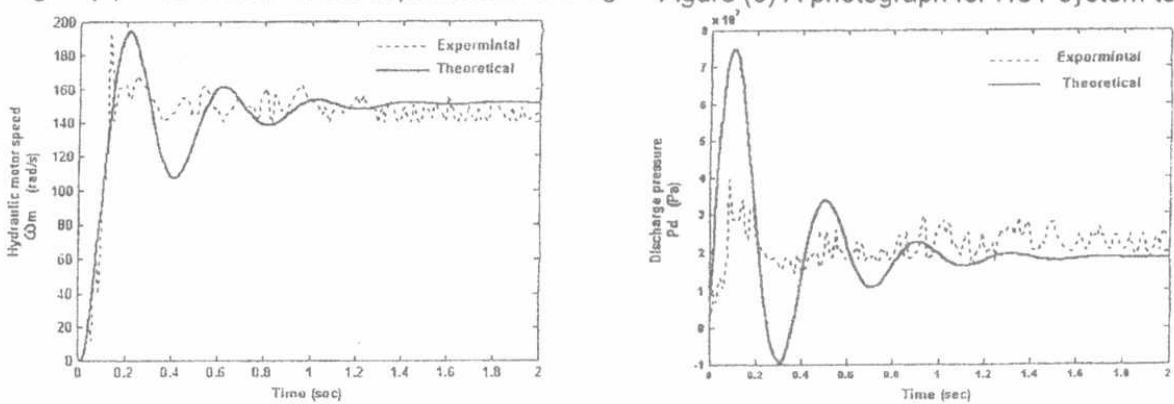

Figure (6) Comparison of hydraulic motor speed $\omega_{m}$, and discharge pressure $P_{d}$ for experimental and simulated results 


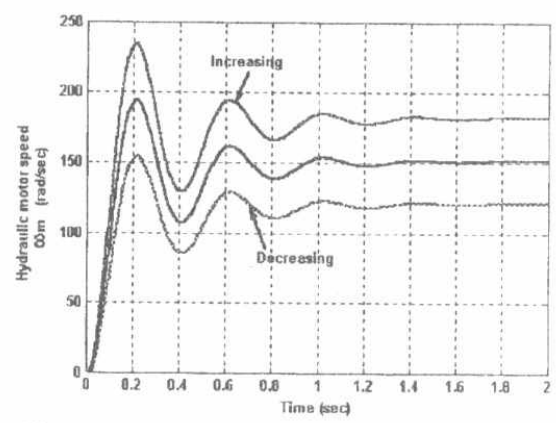

Figure (7-1) Response of hydraulic motor speed due to change of $\omega_{\mathrm{r}}$ by $\pm 20 \%$

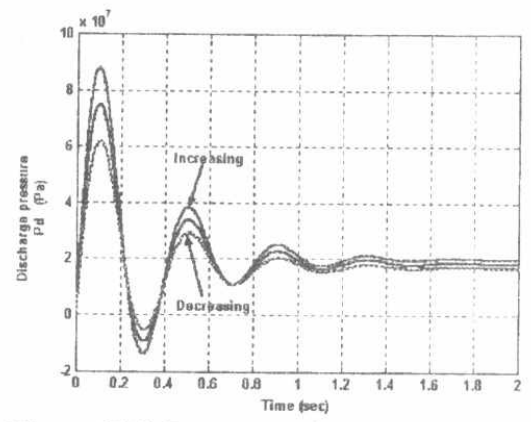

Figure (7-2) Response of discharge pressure due to change of $\omega_{\mathrm{r}}$ by $\pm 20 \%$

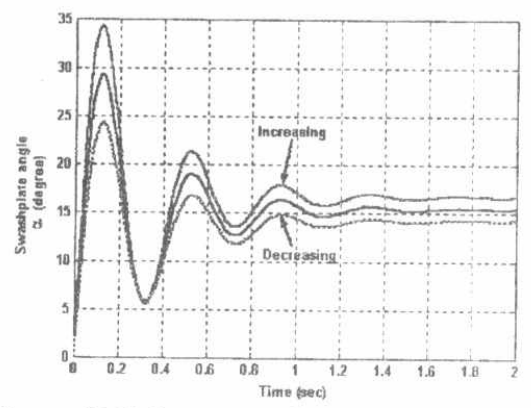

Figure (7-3) Response of swashplate angle due to change of $\omega_{\mathrm{r}}$ by $\pm 20 \%$

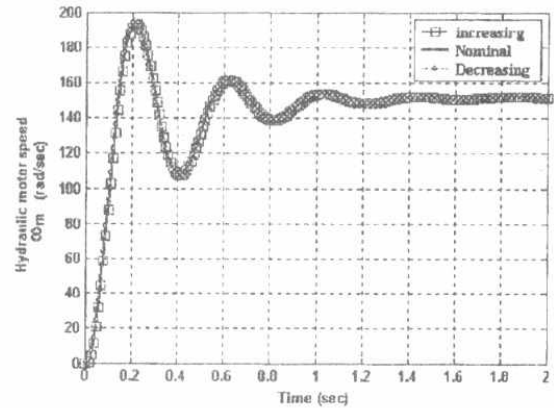

Figure (8-1) Response of hydraulic motor speed due to change of $T_{\mathbf{L}}$ by $\pm 20 \%$

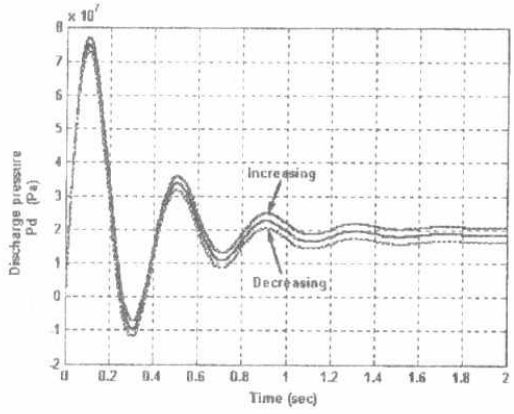

Figure (8-2) Response of discharge pressure due to change of $T_{L}$ by $\pm 20 \%$

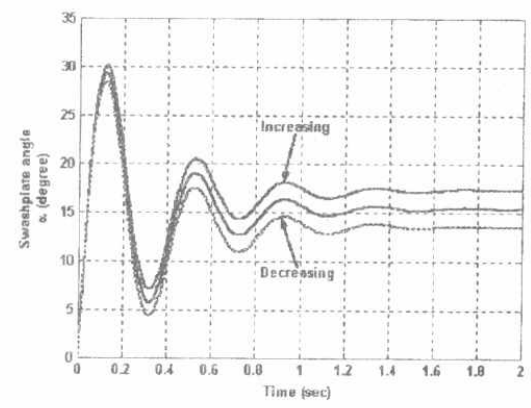

Figure (8-3) Response of swashplate angle due to change of $\mathrm{T}_{\mathrm{L}}$ by $\pm 20 \%$ 


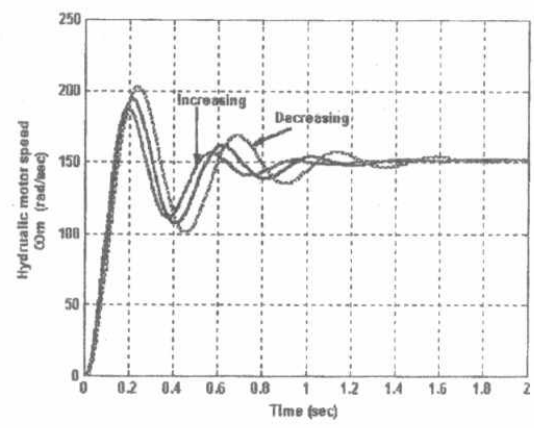

Figure (9-1)Response of hydraulic motor speed due to change of $\boldsymbol{\beta}_{\mathrm{e}}$ by $\pm 20 \%$

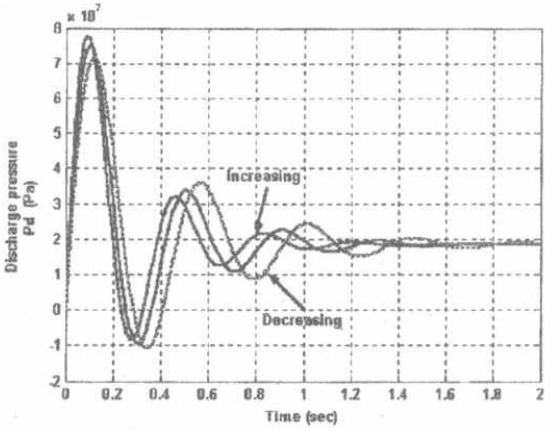

Figure (9-2) Response of discharge pressure due to change of $\beta_{\mathrm{e}}$ by $\pm 20 \%$

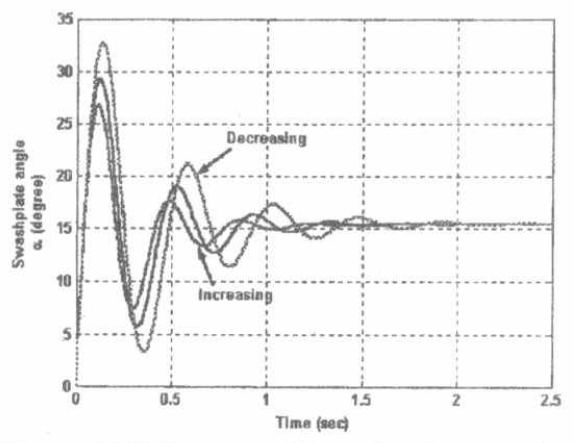

Figure (9-3) Response of swashplate angle due to change of $\boldsymbol{\beta}_{\boldsymbol{e}}$ by $\pm 20 \%$

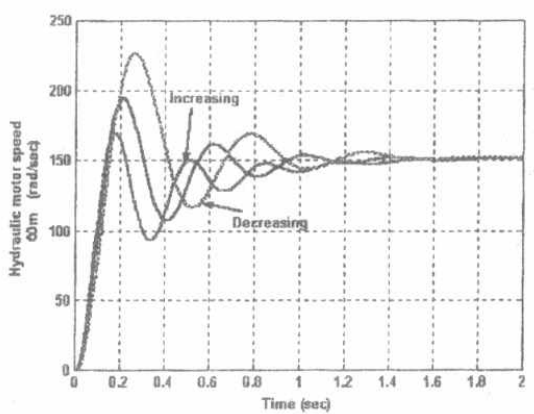

Figure (10-1) Response of hydraulic motor speed due to change of $\mathbf{D}_{m}$ by $\pm 20 \%$

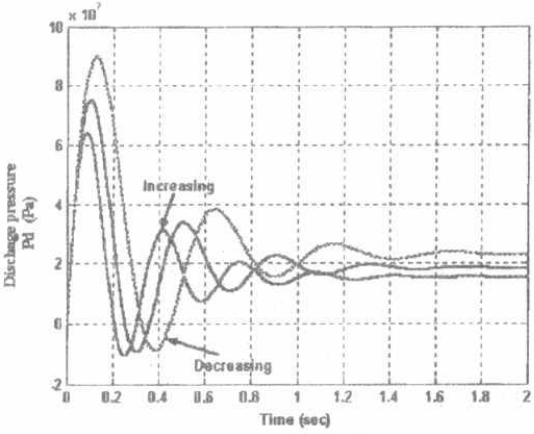

Figure (10-2) Response of discharge pressure due to change of $D_{m}$ by $\pm 20 \%$

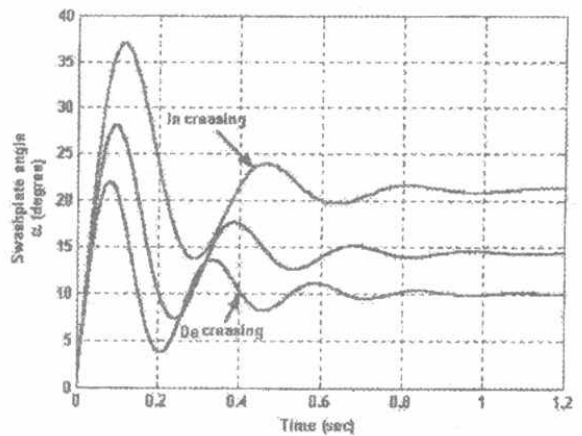

Figure (10-3) Response of swashplate angle due to change of $\mathbf{D}_{\mathrm{m}}$ by $\pm 20 \%$ 


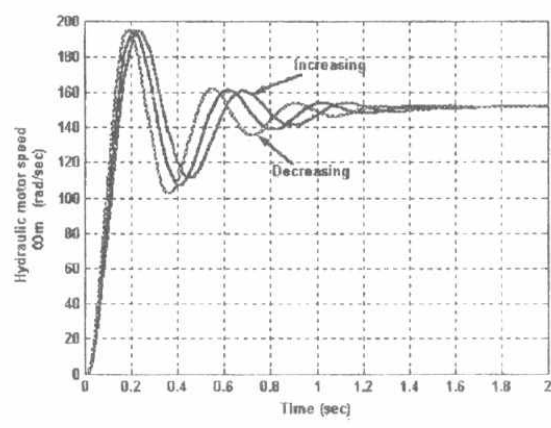

Figure (11-1) Response of hydraulic motor speed due to change of $\boldsymbol{J}_{\mathrm{m}}$ by $\pm 20 \%$

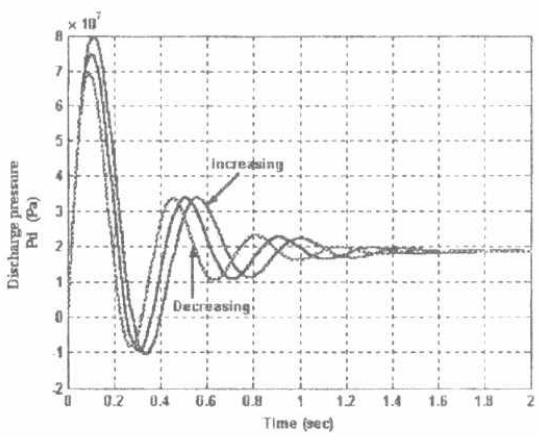

Figure (11-2) Response of discharge pressure due to change of $\mathbf{J}_{\mathrm{m}}$ by $\pm 20 \%$

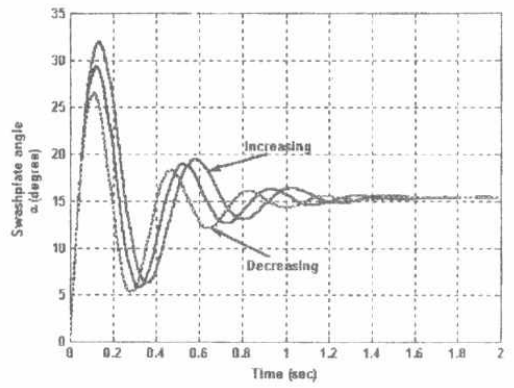

Figure (11-3) Response of swashplate angle due to change of $\mathbf{J}_{\mathbf{m}}$ by $\pm 20 \%$

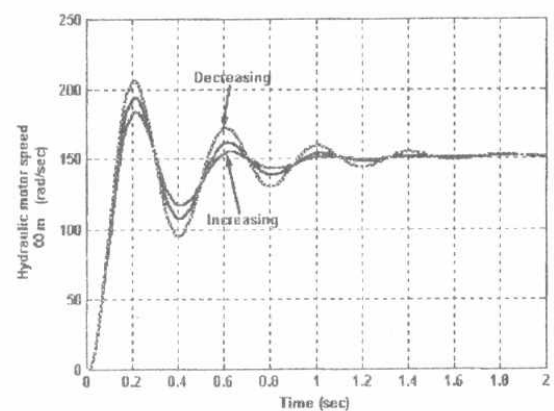

Figure (12-1) Response of hydraulic motor speed due to change of $\mathrm{K}_{\mathrm{L}}$ by $\pm 20 \%$

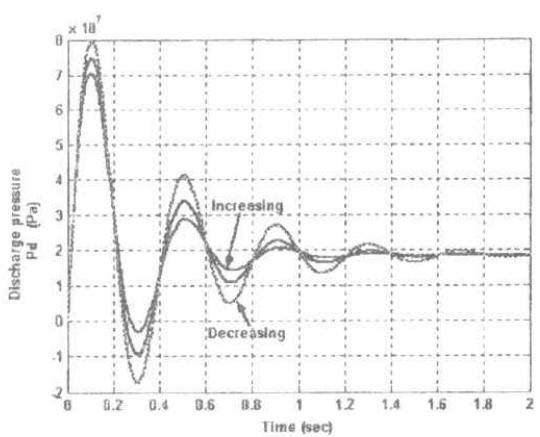

Figure (12-2) Response of discharge pressure due to change of $\mathrm{K}_{\mathrm{L}}$ by $\pm 20 \%$

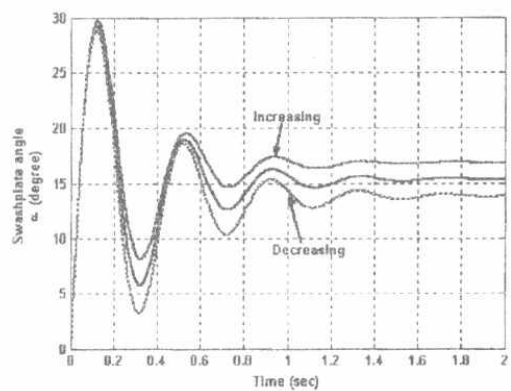

Figure (12-3) Response of swashplate angle due to change of $\mathbf{K}_{\mathrm{L}}$ by $\pm 20 \%$ 


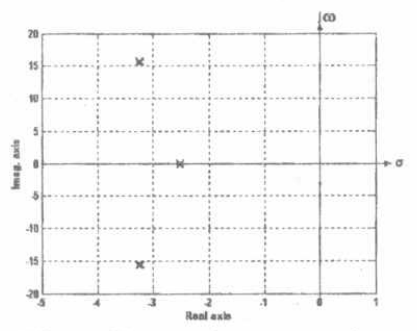

Figure (13-1) Effect of increasing $\omega_{r}$ on the poles location

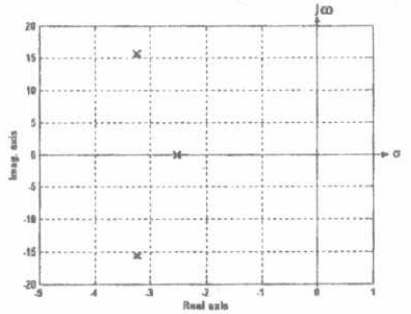

Figure (14-1) Effect of increasing $T_{L}$ on the poles location

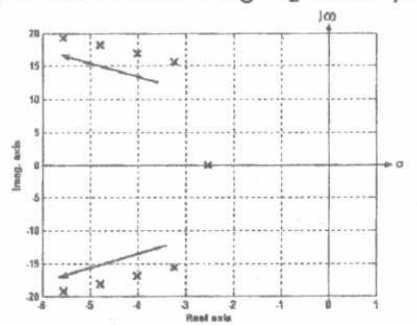

Figure (15-1) Effect of increasing $\boldsymbol{\beta}_{\mathrm{e}}$ on the poles location

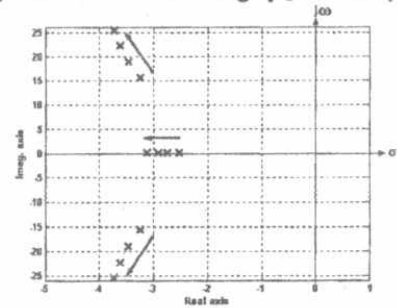

Figure (16-1) Effect of increasing $D_{m}$ on the poles location

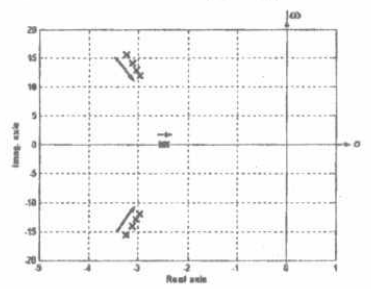

Fig. (17-1) Effect of increasing $J_{m}$ on the poles location

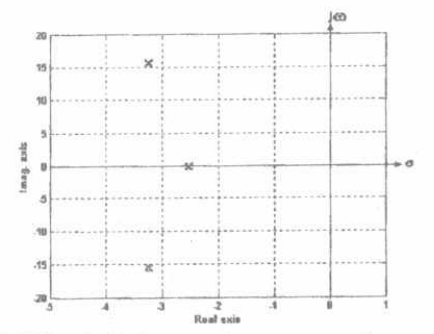

Figure (13-2) Effect of decreasing $\omega_{\mathrm{r}}$ on the poles location

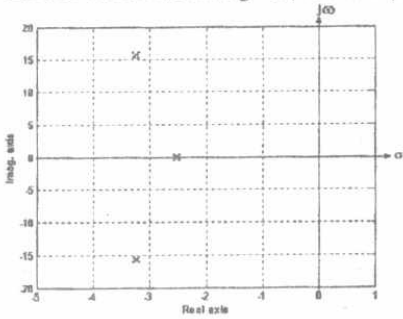

Figure (14-2) Effect of decreasing $T_{L}$ on the poles location

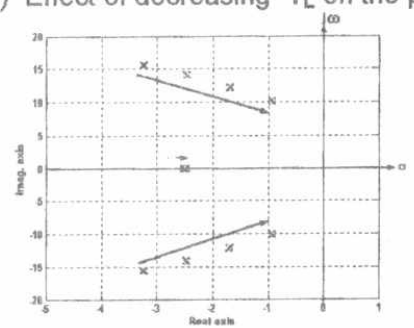

Figure (15-2) Effect of decreasing $\beta_{\mathrm{e}}$ on the poles location

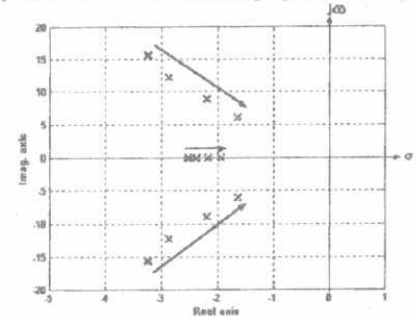

Figure (16-2) Effect of decreasing $D_{m}$ on the poles location

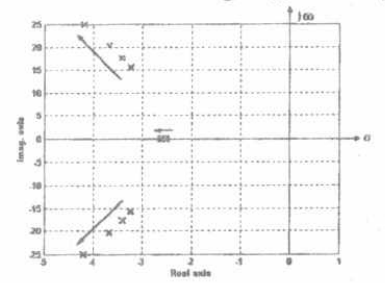

Figure (17-2) Effect of decreasing $J_{m}$ on the poles location 


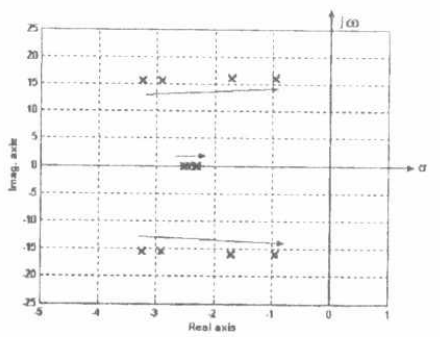

Figure (18-1) Effect of increasing $\mathbf{K}_{\mathrm{L}}$ on the poles location

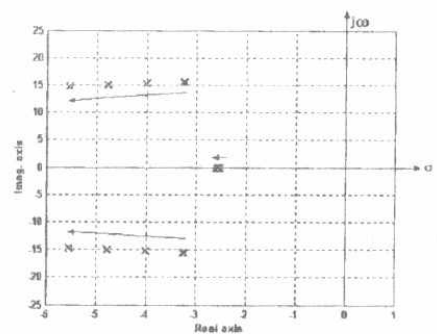

Figure (18-2) Effect of decreasing $\mathbf{K}_{\mathbf{L}}$ on the poles location
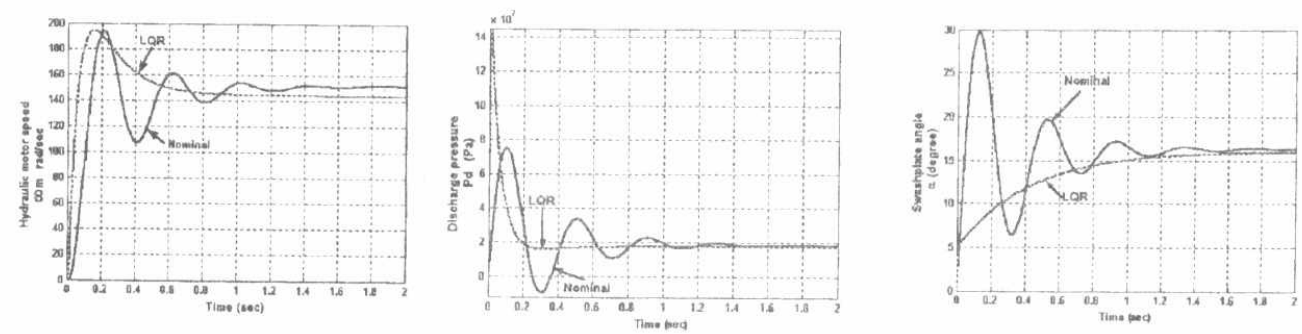

Figure (19) Response of hydraulic motor speed, swashplate angle discharge pressureand verses time with and without LQR

Table (1) Design parameters of HST system investigated in this study:

\begin{tabular}{|l|ll|l|ll||}
\hline Parameter & \multicolumn{2}{|c|}{ Value } & \multicolumn{1}{|l|}{ Parameter } & Value & \\
\hline $\boldsymbol{A}_{\boldsymbol{c}}$ & $1.47 \times 10^{-3}$ & $\mathrm{~m}^{2}$ & $\boldsymbol{L}$ & $6.4 \times 10^{-2}$ & $\mathrm{~m}$ \\
\hline $\boldsymbol{A}_{\boldsymbol{p}}$ & $4.01 \times 10^{-4}$ & $\mathrm{~m}^{2}$ & $\boldsymbol{M}_{P}$ & 0.15 & $\mathrm{Kg}$ \\
\hline $\boldsymbol{C}_{\boldsymbol{m}}$ & 0.49 & $\mathrm{~N}-\mathrm{m} /(\mathrm{rad} / \mathrm{s})$ & $\boldsymbol{N}$ & 9 & - \\
\hline $\boldsymbol{C}_{\boldsymbol{v}}$ & 0.0124 & $\mathrm{~N} /(\mathrm{m} / \mathrm{s})$ & $n_{p}$ & 1450 & $\mathrm{rpm}$ \\
\hline $\boldsymbol{d}$ & 0.00 & $\mathrm{~m}$ & $\boldsymbol{R}$ & $5 \times 10^{-2}$ & $\mathrm{~m}$ \\
\hline $\boldsymbol{D}_{\boldsymbol{m}}$ & 63 & $\mathrm{~cm}^{3} / \mathrm{rev}$ & $V_{C o}$ & $2.07 \times 10^{-4}$ & $\mathrm{~m}^{3}$ \\
\hline $\boldsymbol{D}_{P}$ & 71 & $\mathrm{~cm}^{3} / \mathrm{rev}$ & $\beta_{e}$ & $1.4 \times 10^{9}$ & $\mathrm{~Pa}$ \\
\hline $\boldsymbol{G}_{\boldsymbol{c}}$ & $6.56 \times 10^{-4}$ & $\mathrm{~m}^{3} / \mathrm{rad}$ & $\gamma$ & 0.384 & $\mathrm{rad}$ \\
\hline $\boldsymbol{G}_{\boldsymbol{p}}$ & $0.08 \times 10^{-4}$ & $\mathrm{~m}^{3} / \mathrm{rad}$ & $\boldsymbol{\mu}$ & $3.84 \times 10^{-2}$ & $\mathrm{Ns} / \mathrm{m}^{2}$ \\
\hline $\boldsymbol{J}_{\boldsymbol{t}}$ & 0.198 & $\mathrm{Kg}-\mathrm{m}^{2}$ & $\boldsymbol{\rho}$ & 980 & $\mathrm{Kg} / \mathrm{m}^{3}$ \\
\hline $\boldsymbol{K}_{\boldsymbol{L}}$ & $7.53 \times 10^{-12}$ & $\left(\mathrm{~m}^{3} / \mathrm{s}\right) / \mathrm{Pa}$ & & & \\
\hline $\boldsymbol{k}_{\mathbf{s}}$ & $4.5 \times 10^{4}$ & $\mathrm{~N} / \mathrm{m}$ & & & \\
\hline \hline
\end{tabular}


Table (2) Effect of system parameter variation on the simulation model response.

\begin{tabular}{|c|c|c|c|c|}
\hline $\begin{array}{l}\text { Transient } \\
\text { Specifications } \\
\text { Increasing } \\
\text { Parameter value }\end{array}$ & $t_{r}$ & $t_{p}$ & $\% O S$ & $t_{s}$ \\
\hline$A_{c}$ & $\cong$ & $\cong$ & $\nabla$ & $\nabla$ \\
\hline$A_{p}$ & $\nabla$ & $\cong$ & $\Delta$ & $\Delta$ \\
\hline$\beta_{e}$ & $\nabla$ & $\nabla$ & $\nabla$ & $\Delta$ \\
\hline$C_{m}$ & $\cong$ & - & $\cong$ & $\nabla$ \\
\hline$D_{m}$ & $\cong$ & $\nabla$ & $\nabla$ & $\nabla$ \\
\hline$G_{c}$ & - & - & $\Delta$ & $\Delta$ \\
\hline$G_{p}$ & $\nabla$ & $\cong$ & $\Delta$ & $\Delta$ \\
\hline$J_{m}$ & $\cong$ & $\Delta$ & $\Delta$ & $\Delta$ \\
\hline$K_{e f f}$ & - & $\cong$ & $\Delta$ & $\nabla$ \\
\hline$K_{L}$ & - & $\cong$ & $\Delta$ & $\Delta$ \\
\hline$L$ & $\cong$ & - & $\nabla$ & - \\
\hline$T_{L}$ & - & - & $\Delta$ & - \\
\hline$V_{h}$ & $\cong$ & $\Delta$ & $\Delta$ & $\Delta$ \\
\hline$\omega_{r}$ & - & - & $\Delta$ & - \\
\hline
\end{tabular}

